\title{
Does culture influence learning styles in higher education?
}

\section{Sankaran Manikutty*}

\author{
Business Policy Area, \\ Indian Institute of Management, \\ Ahmedabad, Gujarat 380 015, India \\ E-mail: manikuti@iimahd.ernet.in \\ *Corresponding author
}

\section{N.S. Anuradha}

Department of Management Studies, Indian Institute of Science, Bangalore 560012, India

E-mail: nsanu@mgmt.iisc.ernet.in

\section{Katrin Hansen}

Fachhochschule Gelsenkirchen, Abteilung Bocholt, Fachbereich Wirtschaft, Münsterstr. 265, D-46397 Bocholt, Germany E-mail: katrin.hansen@fh-gelsenkirchen.de

\begin{abstract}
This paper develops a framework for understanding the relationships between approaches to learning adopted by students in the context of higher education and the culture of the country they were brought up in. The paper, after examining the more widely used Kolb's learning styles, opts for another categorisation, namely the so called learning approaches developed by Entwistle and others (for example, Entwistle and Ramsden, 1983; Biggs, 1987; Entwistle, 1992; Tait, Entwistle and McCune, 1998; Biggs, Kember and Leung, 2001). Each of the main categories of learning approaches identified by his school, namely, deep, surface apathetic, and strategic are related to Hofstede's cultural dimensions, namely, power distance, individualism vs. collectivism, uncertainty avoidance, long vs. short time orientation and masculinity vs. femininity and a series of hypotheses developed that could be tested in cross cultural samples. This study would give practical hints on students moving out to study in different cultures (e.g. for higher education) and for teachers dealing with students from multiple cultures.
\end{abstract}

Keywords: approaches to learning; culture; cultural influence; higher education.

Reference to this paper should be made as follows: Manikutty, S., Anuradha, N.S. and Hansen, K. (2007) 'Does culture influence learning styles in higher education?', Int. J. Learning and Change, Vol. 2, No. 1, pp.70-87. 
Biographical notes: Sankaran Manikutty is a Professor of Strategy, Indian Institute of Management, Ahmedabad. Professional Member of The Academy of Management and the Regional Representative for South Asia and the country representative for India, Membership Involvement Committee of the International Management Division of the AOM. Currently engaged in a larger project on culture and learning approaches under a project funded by European Union with other institutions in Austria, Germany, and India. Other areas of research are strategic issues in family firms; telecommunication policy with special reference to convergence, issues in WTO and universal service obligations.

Currently, N.S. Anuradha teaches intercultural communication and crosscultural studies in the Department of Management Studies, Indian Institute of Science. Current areas of research include cross-cultural studies, comparative studies of German and Indian business environments, influence of cultural imprinting on learning styles.

Katrin Hansen is a Professor for Business Studies, FH Gelsenkirchen, Germany. Currently, she is engaged in several projects funded by European Union in cooperation with other institutions in Austria, Germany, and India, Latin America and France focusing cross-cultural learning. Other fields of research are entrepreneurial diversity and diversity management.

\section{Introduction}

We are today witnessing globalisation in education on a scale never seen before. A consequence of this has been the much higher level of student migration. When students enrol into an institution in another country, they are confronted by a new culture, a new educational system, and different learning and teaching styles, while their learning styles have been those imbibed by them in their schooling and early college days. They need to adapt to a very different teaching, collegial learning and administrative styles and in a different culture. For example, while in one culture, students may not be expected to criticise their teachers, or openly differ with their fellow students, in another culture, this may not only be the norm, but even expected (Hofstede, 1986). This transition could be a difficult one for the migrant students as well as the receiving institutions and is likely to influence the performance of students, teaching faculty, and administrators in the host country. As Hall (1990) points out, educational systems are products of the cultures they are embedded in and hence educators will need to be aware of the context in which learning is acquired. This needs an understanding of how approaches to learning and teaching differ across cultures.

The scale of migration of students seeking higher education abroad has increased considerably, and this had led to a melting pot of different cultures in the same class room and in learning groups, which makes the cross cultural learning challenge a steep one. As may be seen from Table 1, between 1998 and 2004, the number of students going to USA for higher education increased by a factor of about 2.5, and that to Australia, UK, and Germany increased by a factor of between five and six. Also, the flow has become more broad-based, with Australia, UK, and Germany becoming major destinations. Hence, preparing to learn in a different environment has become a very important 
element in the preparation of a student planning to emigrate for higher studies, especially if he/she is moving into a country with a very different culture.

Research on how people learn has captured the interest of academicians across disciplines over several decades and continues to generate a vast body of empirical and theoretical work resulting in refinement of existing conceptualisations of learning patterns, and devising better and different instruments for measuring learning patterns. It has been argued that teachers could employ this knowledge to gain a better understanding of the complexity of differences in learning behaviours that they experience in their classrooms, even within one country (Coffield et al., 2004).

Table 1 Number of students from India going to Institutions of Higher Education in Different Countries, 1998-2002

\begin{tabular}{lrrrrrrr}
\hline Target Country & 1998 & 1999 & 2000 & 2001 & 2002 & 2003 & 2004 \\
\hline Australia & 3613 & n.a. & 4578 & 6195 & 9539 & 12384 & 15742 \\
Austria & 96 & 95 & 98 & 104 & 78 & 75 & 80 \\
Germany & 899 & 1004 & 1282 & 1412 & 2196 & 3429 & 4237 \\
United Kingdom & 3112 & 3922 & 3962 & 4302 & 6016 & 10422 & 18026 \\
United States & 30270 & 34504 & 39084 & 47411 & 66836 & 74603 & 79736 \\
\hline
\end{tabular}

Source: Schmalzer and Neubauer (2007).

\section{Scope of the paper and the research questions addressed}

At the outset, we wish to make a distinction between learning styles and approaches to learning. Learning styles is a term closely associated with the work of Kolb (1984), and refers to a more general and higher level of preferences for particular modes of learning, while learning approaches refers to more situation specific competencies required for effective learning, especially in student courses (Entwistle and Wilson, 1970), or the way a student prefers to tackle a learning task in the light of the perceived demands (Entwistle, Hanley and Hounsell, 1979). In this paper, our focus is on approaches to learning and our objective is to explore the relationship between the dominant approaches to learning in different cultures and the generic attributes of the cultures. Though quite some work has been done on learning styles and their determinants, much less work seems to have been done on approaches to learning adopted by students and their relationship to the embedded cultural context. Though Kolb's learning styles are essentially highly individual dependent, some patterns of learning styles have also been observed across different countries (Jaju, Kwak and Zinkhan, 2002), but most of such studies have addressed the issue of learning styles across specific cultures (more specifically, across specific countries) and have stopped short of generalising the results to more generic cultural attributes of the countries. On the other hand, approaches to learning are dependent upon a variety of variables, such as the learning context, the incentives to learning and experimentation, consequences of failure and so on as may be seen from Entwistle's work. In a broader sense, these variables subsume into the generic characteristics of a country's culture and hence Entwistle's constructs on approaches to learning lend themselves to the development of a theoretical framework that can be easily and reliably tested. In this paper, we propose to develop such a framework linking cultural attributes of a learner group to their approaches to learning. Thus, the theoretical 
question addressed in this paper is: "What is the relationship between the dominant approaches to learning of the members of a country/community and the culture of that country or community?' To answer this question, we develop a series of hypotheses linking different approaches to learning to different attributes of culture. This is an analytical, and not an empirical paper; it only develops a framework that could be used for empirical testing.

It is important to note that we have used the phrase 'country or community'. This is because studies of culture are all aggregates of a country and neglects the considerable variations that could exist within a country in different regions, occupations and education levels. Hence ideally, a researcher should validate the country scores within the particular community sample he/she is working on.

\section{Culture and its dimensions}

We adopt Hofstede's definition of culture as:

"the collective programming of the mind that distinguishes the members of one group or category of people from another" (Hofstede, 2001).

Members of a society function according to culturally determined implicit models in the minds of their members (Hofstede, 2001). Based on attitude surveys of IBM employees in more than 50 countries, Hofstede $(1980,2001)$ empirically identified five dimensions along which culture can be distinguished. These dimensions are: power distance, uncertainty avoidance, masculinity vs. femininity, long-term vs. short-term orientation, and individualism vs. collectivism. Hofstede ranked countries according to their scores on each of these dimensions. We would argue that all the five dimensions have implications for approaches to learning in so far as cultural patterns in the society are reflected in the cultural patterns of the learning environment.

Individualism vs. collectivism refers to the degree to which individuals are expected to look after themselves or remain integrated with their family or colleague groups. Studies have revealed that differences in childhood socialisation between individualistic and collectivist societies lead to differences in modal personality characteristics and in behaviour patterns amongst family members (Hofstede, 2001). Those who grow up in collectivistic societies learn to intuitively think of themselves as part of a group focusing on 'we'. In contrast, those who grow up in individualistic societies learn to think of themselves as an individual with a focus on 'I' (Hofstede, 2001). Unquestioning loyalty is expected and assumed in highly collectivistic cultures, while individual excellence is nourished and celebrated in individualistic cultures. In collectivistic cultures, harmony in the group is encouraged, and great emphasis is placed on group norms.

Power distance is the extent to which the less powerful members of organisations and institutions accept and expect unequal distribution of power. In a learning context, this means the relationship between teachers and students. It is to be noted that this dimension does not refer to the power teachers have as such, but rather, the distance this power implies.

Hofstede (1986) has argued that the above two dimensions play the most important roles in determining teacher student relationships.

Uncertainty avoidance relates to the level of stress in a society in the face of an unknown future. It refers to the way uncertainties are viewed and taken care of. For 
example, in societies having a high degree of uncertainty tolerance, rules may be specified loosely, and infractions viewed more leniently. In societies with a low tolerance to ambiguity, rigid rules and procedures tend to be specified so as to ensure a high predictability of behaviour, any 'loose ends' being viewed as aberrations needing attention.

Masculinity vs. femininity relates to the division of emotional roles between men and women. It manifests itself as aggressive vs. more 'obedient' behaviour. This is to be distinguished from male dominant vs. gender egalitarian societies. 'Feminine' societies in Hofstede's typology could be quite male dominant, as for example, Japan and Korea; 'masculine' societies such as USA, on the other hand, could be much more egalitarian in terms of gender. Long vs. short-term orientation relates to the extent to which a culture programmes its members to accept delayed gratification of their material, social, and emotional needs (Hofstede, 2001). In cultures with long-term orientation, results are not seen as 'here and now'; waiting for longer term benefits is acceptable and even encouraged. Long-term orientation also reflects a firm belief in tradition.

A more recent study to identify the cultural characteristics of countries has been that by GLOBE (House et al., 2004). This has been a much more extended survey involving 62 societies between 1994 and 1997. They extend Hofstede's dimensions in two ways: first by introducing a distinction between 'as is' and 'as it should be' constructs for each of the dimensions. Secondly, they have identified nine constructs, of which four are the same as Hofstede's and one involves a splitting of one construct. For our discussion, we felt that the GLOBE dimensions may not add much value as compared to the much simpler dimensions by Hofstede. The ability of human mind to process simultaneously the numerous dimensions of GLOBE may be limited, and though one of the authors has been an enthusiastic supporter of the GLOBE study and its insights, at least for an exploratory research of this kind, we felt parsimony will be important to get a broad picture of the relationships involved and hence we have developed our paper based on Hofstede's dimensions. However, a researcher could test his/her results using both GLOBE as well as Hofstede's results for each country, and additional insights would be very welcome.

\section{Learning styles and approaches to learning: overview of literature}

Research on how people learn can be broadly fitted into streams, one developed by Kolb and his colleagues (for example, Kolb, 1976), and the other by Entwistle and others (for example, Entwistle and Wilson, 1970). Though we do not propose to use Kolb's model, no paper on learning would be complete without referring to the work he and his colleagues have done over the years. So influential has been his work that more than 1900 studies have been spawned or influenced by his theory in the last 30 years (Experienced Based Learning Systems, 2007). Hence, we propose to present the essentials of Kolb's approach and then proceed to show why we have not adopted his model, and rather chosen a much less used one.

Kolb's categorisation of learning styles is essentially an experiential learning model, linked to the personality of the learner. The initial ideas for their categorisation were drawn from the work of Piaget (1952) who defined intelligence as the balance between the process of fitting concepts to external world (accommodation) and the process of fitting observations of external world into a conceptual schema. Kolb and his colleagues 
developed these ideas further, on the hypothesis that learning involves four activities, namely, feeling, reflecting, thinking, and doing. These could further be seen as leading to two basic components of learning, namely, how people form their ideas, whether through concrete experience, or abstract conceptualisation, and how they process these ideas further: through active experimentation or reflective observation (Kolb, 1985). These two dimensions were considered to be independent, resulting in four styles of learning. Stated differently, a combination of two learning abilities given above constitutes a particular learning style (Kolb and Fry, 1975; Kolb, 1984). Four learning styles were thus conceptualised:

1 Converging learning style, combining Abstract Conceptualisation (AC) and Active Experimentation (AE) in which learners tend to solve specific problems, and predominantly employ a hypothetical deductive reasoning.

2 Diverging learning style, combining Concrete Experience (CE) and Reflective Observation (RO) in which learners tend to solve problems by viewing situations from many perspectives and rely upon generation of new ideas through techniques such as brain storming.

3 Assimilating learning style which combines $\mathrm{AC}$ and $\mathrm{RO}$, and the learners tend to solve problems through an inductive process, and develop theories to fit their observations.

4 Accommodating learning style which combines CE and AE, and the learners tend to solve problems through empirical experiments validated through data and observations. Kolb's categorisation may be seen from Figure 1.

Figure 1 Kolb's four styles of learning

\begin{tabular}{|c|c|c|}
\hline & Concrete experience (CE) & Abstract conceptualisation (AC) \\
\hline $\begin{array}{l}\text { Reflective } \\
\text { observation (RO) }\end{array}$ & \begin{tabular}{l}
\multicolumn{1}{c}{ Diverging learning style } \\
Strengths: Imaginative ability, \\
viewing a problem from \\
multiple perspectives and \\
ability to organize these views \\
into a coherent picture \\
Mode of solving problems: \\
Generation of multiple ideas, \\
exploring many possible \\
solutions
\end{tabular} & $\begin{array}{l}\text { Assimilating learning style } \\
\text { Strengths: Developing } \\
\text { theoretical models; assimilating } \\
\text { disparate observations into an } \\
\text { aggregate explanation } \\
\text { Mode of solving problems: } \\
\text { Watching, reflecting and } \\
\text { inductive procedures }\end{array}$ \\
\hline $\begin{array}{l}\text { Active } \\
\text { experimentation } \\
\text { (AE) }\end{array}$ & $\begin{array}{l}\begin{array}{c}\text { Accommodating learning } \\
\text { style }\end{array} \\
\text { Strengths: Doing new things, } \\
\text { new experiences, carrying out } \\
\text { plans and experimenting; } \\
\text { excel when they have to adopt } \\
\text { to new situations. } \\
\text { Mode of solving problems: } \\
\text { Through intuitive, trial and } \\
\text { error manner }\end{array}$ & $\begin{array}{l}\text { Converging learning style } \\
\text { Strengths: Practical application } \\
\text { of ideas, learning by doing and } \\
\text { thinking; hypothetical deductive } \\
\text { reasoning } \\
\text { Mode of solving problems: } \\
\text { Unemotional, deductive, logical } \\
\text { reasoning }\end{array}$ \\
\hline
\end{tabular}


The four phases: feeling, reflecting, thinking, and doing constitute four stages in a learning cycle that go in sequence, each building on the earlier stage; but depending upon the inherent learning styles of individuals, the emphasis placed on different stages differ. Kolb does not explicitly recognise this, but the learning could just be single-loop learning, in which individuals, groups, or organisations modify their actions according to the difference between expected and obtained outcomes, or it could be double-loop learning, in which the entities (individuals, groups, or organisation) question the values, assumptions and policies that led to the actions in the first place; if they are able to view and modify those, then second-order or double-loop learning has taken place. Double loop learning is the learning about single-loop learning (Argyris and Schon, 1978).

To measure the learning styles of an individual, Kolb and his colleagues developed the well known Learning Style Inventory. They have also developed related inventories such as Boyatsis-Kolb Adaptive Style Inventory and Boyatsis-Kolb Learning Skills Profile.

Though Kolb's basic ideas have influenced subsequent thinkers deeply, many scholars have not agreed to the basic structure of the actual instrument developed by him. For example, Honey and Mumford (1982) focused on observable behaviour rather than the psychological basis for that behaviour, and proposed four types, activists, reflectors, theorists, and pragmatists. A predisposition to a particular style of learning is in this case more of an individual than a collective trait.

The major contribution of Kolb has been his challenge to the earlier learning models that sought to reduce learning styles and abilities to one dimension of personality, such as intelligence. They also do not recognise any one style as superior to another; all styles have their positive and negative points; the important thing is how comfortable the learner is with his/her style.

Kolb's model, though widely used by scholars, has been criticised on different counts (for example, Smith, 2001). From our point of view, the major problem is that experiential learning is not the only way people learn; other ways such as information assimilation and memorisation exist and are very important, especially in classroom situations (Jarvis, 1987). Also, being closely related to the basic personality of an individual, despite the attempts by many scholars, the model really does not seem to lend itself to theorising about how Kolb's learning styles could vary across cultures.

A modification of Kolb's model has been proposed by Jarvis $(1987,1995)$. While this model introduces more factors such as non-reflective learning, and hence is an improvement over Kolb's model, it still retains the problems with Kolb's model that we have noted above.

The second stream of research on how people learn revolves around the idea that not only the personality of the learner, but also the learning environment determines the way a student approaches learning. These include a variety of influences such as the admission processes, the encouragement shown to different kinds of learning (are grades given for originality or for reproducing facts?), the teaching styles of faculty and so on, and these have been labelled by these researchers as 'throughlines'. Thus, how a learner approaches a learning task is dependent upon both the personality and the setting in which the learning takes place. The researchers in this stream concentrate on the individual learning strategies adopted by students, and they prefer to describe them as 'learning approaches' rather than as 'learning styles'. The earliest work in this stream was perhaps the one by Entwistle and Wilson (1970), refined in 1977. They identified two kinds of motivation for learning: achievement oriented and led by fear of failure. Marton 
and Saljö (1976) developed the notions of deep and surface learning, further developed by Entwistle and Ramsden (1983), Biggs (1987), Entwistle (1992), Entwistle and Tait (1995), Tait, Entwistle and McCune (1998), Biggs, Kember and Leung (2001), among others. Pask (1976) developed the idea of holistic vs. serialist learning strategies. Entwistle and Ramsden (1983), through factor analysis of data gathered from about 2000 students, identified four main orientations to studying: meaning orientation, reproducing orientation, achievement orientation, and 'non-academic' orientation. These streams got integrated into three categories of learning: deep, surface apathetic, and strategic. These approaches to learning are based on what motivates the learner: intrinsic motivation to understand and assimilate learning, extrinsic motivation led by a fear of failure, and achievement motivation leading to proper organisation of studies, and a goal oriented approach to studying (Entwistle, Hanley and Hounsell, 1979). The main difference of this research stream from the first stream is that deep, surface apathetic or strategic learning approach is not the result of the attributes of individuals alone, but is also influenced by the culture and the learning environment. In this approach, the quality of learning achieved by students is determined by two broad factors:

1 the students' characteristics

2 the learning environment, which is influenced by the culture of a society, but is not solely determined by it.

The deep approach to learning requires both relating ideas (holist) and using evidence (serialist; Pask, 1976), in other words, a versatile style in learning. It also entails an interest in new ideas and a willingness to explore them in-depth. Deep learning involves a combination of reflective as well as active learning; it really addresses itself to how deeply a student tends to go into a given subject to gain a deep and thorough understanding in all its dimensions. Deep learning has been further broken up into four subscales by researchers (Marton, Hounsell and Entwistle, 2005):

- $\quad$ seeking meaning

- relating ideas

- use of evidence

- interest in ideas.

The surface apathetic approach is characterised by learners tending to focus on memorisation, being extrinsically motivated by the fear of failure, and focus strictly on the task at hand. The learners tend to be bound to the syllabus and typically gain only a shallow understanding of the subject. Whereas, deep learners try to create meaning and understand the coherent whole, are intrinsically motivated, and relate previous knowledge to new knowledge, the surface apathetic learners tend to focus on the more obvious aspects of a problem than its deeper aspects. Marton, Hounsell and Entwistle (2005) identify the following subscales for the surface approach:

- lack of purpose

- lack of understanding

- syllabus-boundedness

- fear of failure. 
In addition to the deep and surface approaches, Biggs (1987) and Entwistle (1992) identified a third approach to learning, the achieving, or sometimes also called strategic approach. The strategic approach shows a link between the learning approach adopted and the motive for the learning, the latter being associated with both organised studying and time management (Atkinson and Feather, 1966). In their learning behaviour, strategic learners aim to obtain the highest possible grades or other rewards, serving their own set of objectives. A good example is that of an MBA student whose objective is to get a job on the Wall Street: this student would concentrate and do well on those courses he/she would feel important in getting that job; the rest of the courses may be given only such time as needed to get an overall pass. Strategic learners identify assessment criteria for courses and then adopt the appropriate study methods, organising their studies well. It is a 'goal directed learning', where the goals are concrete and clear: the following are the components of the strategic approach identified by Marton, Hounsell and Entwistle (2005):

- organised studying

- time management

- achieving motivation

- monitoring effectiveness.

Strategic learning is to be distinguished from surface learning. While in surface learning, a student does not get interested or is moved by fear of failure, in the case of surface approach, the students are directing their learning to achieve some external goals other than learning itself. Thus, strategic learners may get good grades, and even achieve substantial learning especially in courses that are strategically important to them, and yet fail to achieve any deep learning even in those courses. Similarly, deep and surface apathetic approaches are not mutually exclusive; studies by Entwistle, Tait and McCune (2000) have confirmed the independence of these three approaches.

As we have noted earlier, Kolb's framework has problems and being a model to study learning styles at an individual level, it does not appear to give a good conceptual foundation to study how learning styles might differ among different cultures. We have preferred Entwistle's framework for our paper, although Kolb's model is much better known and more widely used, for four additional reasons. Firstly, as we have noted earlier, Kolb's framework is built in the context of experiential learning. We are not sure that this basic assumption of experiential learning holds good in higher education in many situations. Secondly, having chosen to pursue a much less trodden path, we hope to initiate a new line of enquiry that could possibly lead to an integration of the two approaches we have outlined. Thirdly, Entwistle's approach seems to depend less upon individual personalities of the learners than Kolb's and gives greater weightage to the learning context. Hence, for the purposes of making cross cultural comparisons, Entwistle's model may be more appropriate. Of course, this will be validated only after an actual study. Finally, Entwistle's model also seems to hold better promise to be able to develop concrete suggestions to students emigrating to other cultures and to teachers dealing with multi-cultural classrooms, so that they could adapt their learning styles/teaching styles. 
In the following pages, we now proceed to develop our hypotheses on how culture could affect learning styles, and then propose a research design for testing the propositions, using Entwistle's model.

\section{Impact of culture on learning}

Pratt (1992) argues that learning styles may vary from culture to culture. A modest body of the recent interdisciplinary research in this area aims to enhance our understanding of how learning styles or approaches vary across cultures (De Vita, 2001; Ramburuth, 2001; Paul and Arcodia, 2002; Morse, 2003).

If culture is understood as an all-pervading shared set of assumptions, values and behaviour, a consequence is that phenomena such as learning and studying, though taking place at the level of individuals, are also embedded in the logic of that particular culture, and hence reveal collective patterns at a macro level. We now relate the cultural dimensions to the three approaches to learning.

\subsection{Power distance}

We take up this first because it, along with collectivism, could have the maximum impact on learning approaches if we go by the arguments of Hofstede (1986) in the context of student-teacher relationships. A highly power distant society clearly expresses certain social hierarchies that are acceptable to the society. Therefore, not surprisingly, a teacher is ranked higher than his/her students in terms of the knowledge and authority vested in $\mathrm{him} / \mathrm{her}$. His/her 'wisdom' and teachings are taken as highly authentic and are not questioned (Hofstede, 1986, 2002). Thus, class discussions would tend to be more in the nature of clarifications rather than active debating on what the teacher has taught. Students 'look up' to their teachers as having the last word in everything they teach. For example, in India which ranks high in power distance, there are prayers that equate the mother, father, and teacher to God. Therefore, students try to internalise the knowledge handed down by teachers through memorising. This is reproduced later with an intention of pleasing the teacher.

Deviants are likely to be ridiculed or even ostracised as they are perceived to be rebels or trouble makers. As for teachers, they are expected to teach with authority and with a degree of confidence in the knowledge that they possess about their discipline. Since students rely on the teachers completely, everything that is relevant needs to originate from the teacher. If 'autonomous learning' is expected from students (as for example, projects involving creative application of principles), then the students' perception of what their teachers want will influence the outcome. Thus, the approaches to learning in societies with different power distances can be expected to differ.

Deep learning requires extensive original effort and thinking, and such a process necessarily leads to different outcomes (not a standardised outcome). As suggested by Hofstede (1986), students would be conditioned from childhood to accept what the teacher says rather than thinking for oneself. Thus the students, even in a different culture, would be simply too shy or scared to question the teachers, come out with original answers or extend the point to unfamiliar situations. In a study, teachers from a Western society, with a low power distance, in a rather subjective recounting of their experiences of teaching in Japan and Thailand, stated that the Japanese and Thai students 
were relatively (as compared to Western students) more passive, not used to teacherstudent interaction, preferred not to work individually, and avoided giving definite conclusions (Kainzbauer and Haghirian, 2005). They tended not to be critical of the teacher, a person held in very high esteem in Japan and Thailand. Even between Japanese and Thai students, the former (a higher power distance society) showed a far less critical attitude to their teachers as compared to Thai students. An EU-ASEAN research project on learning styles also showed significant differences between Asian students (Singapore and Thailand) and European students from Austria and Germany along the expected dimensions. Significant differences were found also between Singapore and Thailand, Singapore (a higher power distance society) being strictly against criticising professors while Thai students were more at ease concerning this (Hansen and Keuchel, 2005). Thus, we hypothesise that:

Hypothesis 1: The higher the power distance in a society, the more will the learning approach tend to be surface and less to be deep.

\subsection{Individualism vs. collectivism}

The most important feature of a collectivist society is the mutual support members of this society tend to give to one another. In a class room, this means not openly contradicting a fellow student, going by what appears to be the class consensus rather than by one's own logic, emphasis on avoidance of loss of face by either the teacher or the fellow students (losing an argument is seen as loss of face) and seeing education itself as a means of improving one's status in a society. Hofstede (1986) suggests that in collectivist societies, certificates obtained at the end of a programme are highly valued, and students work hard to ensure that they get these. In Entwistle's categorisation, they would be labelled as strategic learners. Auyeung and Sands (1996) suggest that the conception of self differs in collectivistic cultures such as Hong Kong and Taiwan as compared to individualist cultures such as Australia. Confucian values encourage Chung Yung or the doctrine of the mean, encouraging people to avoid extreme stands, and this discourages creative learning (Taylor, 1990). In collectivist societies, knowledge is seen as a commodity to be transferred from a teacher to a student, the teacher and the student are seen as a collective, and the individual understanding of the students is not important (Auyeung and Sands, 1996). Clearly, this implies a discouragement of deep learning. Ingelhart and Oyserman (2004) postulate that in collectivist societies meaning is contextualised while in individualist societies it is decontextualised. The key to the difference in the learning processes lies in the way information is synthesised and processed. In collectivistic, high context societies, intuitive understanding of a situation plays a very important part. Knowledge is embedded in a situation, and things are seen as connected and interdependent. Multiple sources are used, and modelling, practicing, and demonstrating are very important components of learning (Von Queis, 2005). In the studies examined by Yamazaki (2005), this proposition is generally supported. When examined in the context of higher education, this indicates that education in highly collectivistic societies tends to focus on relationships rather than content, so that nurturing contacts and building networks become very important. The stress is on belonging to a group. Regional, linguistic, and filial affiliations will be quickly established, thus fostering small collectives having similar identities. Oyserman, Coon and Kemmelmeier (2002) also cite 
Miller and Biersoff who in their research showed that Indian students, due to a high degree of collectivism, prefer conflict solving solutions that are interpersonal.

A related, but not the same, classification is the shame vs. guilt culture proposed by Benedict (1946). In the so called shame cultures (such as Japanese), the possible criticisms from the audience and peers are taken very seriously, and behaviour is moulded on avoidance of such criticism as far as possible. In guilt cultures, on the other hand, the actions are determined by whether they conform to a set of internal norms that may be called conscience. Evidently, this attitude is linked to the degree of collectivism in societies. In highly individualist societies, reflections on what one is doing or going to do, the internalised criticism and internal verbal expression (Emde and Oppenheim, 1995) play an important role, thus leading to a deep learning pattern based on reflective observation, as Yamazaki proposes (2005). In shame cultures, on the other hand, one would expect to see more of surface learning prompted by collective norms.

A different line of understanding the possible differences in learning styles between people of different cultures is provided by the work of psychologists such as Nisbett (2003). Here, the comparison between Western and oriental societies is not on the basis of the cultural dimensions discussed above as such, but as an offshoot of the languages in different countries, rooting their arguments on the so called linguistic determinism. Nisbett found differences in the way in which persons in Western and Eastern societies process knowledge and information. According to him, the former tend to categorise objects and use a formal deductive and inductive reasoning process, whereas the Eastern societies tend to think more in terms of informal (or less clearly defined) processes and relationships, a consequence of collectivism.

These lines of arguments also lead to basically the same conclusion: high context based interpretation of concepts would imply an inability to get deep into the meaning of the concepts and their relationships; rather the emphasis would be on interpreting other's ideas, assuming a certain contextual meaning and not going deeper, in other words, a more surface and strategic learning (more strategic because the concrete results such a passing examinations, getting grades and ensuring one's 'certificates' would be of prime importance in collectivist societies).

Thus, we hypothesise that:

Hypothesis 2(a): The more collectivist a society, the higher will be the tendency of learning approach to be surface and strategic.

Hypothesis 2(b): The more collectivist a society, the lower will be the tendency of learning approach to be deep.

\subsection{Uncertainty avoidance}

In societies with a high degree of uncertainty avoidance, students are comfortable only with precise objectives, structured learning, detailed assignments, strict time tables, and an unambiguous assessment (Hofstede, 1986, 2002). They will have a decided tendency for adopting a strategic learning that is congruent with their goals. The students will try to gather as much of information on a topic as possible, will refer to sources of information other than those mentioned by the professor to confirm the veracity of what is being said and will prefer to reason out things by themselves. This may be lead to strategic as well as deep learning styles. There may be a certain willingness to get out of the rigid syllabus and a desire for deep learning that is manifest in students of societies with high 
uncertainty avoidance. The opposite is true in societies with a low degree of uncertainty avoidance. Deep learning is a very satisfying process that reduces uncertainties, and a high degree of structuring will decrease uncertainty, For example, teachers may resort to multiple choice questions rather than those that require a high degree of subjective assessment and is liable to be challenged; they may give a large number of highly structured exercises that give an appearance of learning, but in fact simply restrain thinking. More structured exercises also mean more focused preparation, making a more pragmatic learning style more likely. Thus, we hypothesise that:

Hypothesis 3: The higher degree of uncertainty avoidance in a society, the more will the learning approach tend to be strategic and deep to moderately deep, and less will it tend to be surface.

\subsection{Long vs. short-term time orientation}

In societies with a short time orientation, the benefits of deep learning may not be apparent or appreciated (Hofstede, 2002). There is a lot of emphasis on practice and good behaviour as specified by the tradition in that culture. Therefore, education in societies with long time orientation is viewed as gathering of information that is necessary to acquire the skills that are necessary for the long-term goal of finding a well-paid job. The content of education, in other words, is a source of information and the context of education is for establishing long lasting relationships. In such societies, relationships take precedence over everything else so much that there will be a strong tendency to establish networks within the education system that will be profitable in the future either at a professional and/or personal level. These factors might tend to breed surface rather than deep learners.

On the other hand, a strong 'future' or long-term orientation may lead to students appreciating the benefits of deep learning which they would perceive as being beneficial in the long run. This could lead to a deep approach to learning.

Strategic learning could be argued as being adopted by both the cultures. In a shortterm oriented culture, students may set their grades and perhaps even rank as their goal, and work systematically towards that; but in a long-term oriented culture, students may perceive the long-term goals as getting a good understanding of the subject, and hence work towards this goal.

Thus, we hypothesise that:

Hypothesis 4: The higher the short-term orientation of a society is, the more will the learning approach tend to be surface, and less to be deep. There will be no difference as regards strategic learning between long and short time oriented cultures.

\subsection{Masculinity vs. femininity}

It has to be reiterated that Hofstede's distinction between masculine and feminine cultures does not point to gender egalitarianism, but to assertiveness, competitiveness, and higher ambition as characterising a masculine society. Masculine societies tend to place a great importance on tangible success. In a learning situation, in masculine societies, teachers openly praise good students, set best students as the benchmark, reward good performance very well, and create an intense, though a stressful climate 
(Hofstede, 1986). Clearly, this contributes to a pressure for deep and strategic approach to learning. We do not propose any hypothesis regarding its impact on surface learning.

Hence, we propose that:

Hypothesis 5: The more masculine a society is, the more will the learning approach tend to be deep and/or strategic.

Figure 2 gives an overview about the hypotheses concerning the effect of culture on approaches to studying and learning.

Figure 2 Hypotheses developed at a glance: relationship matrix

\begin{tabular}{|c|c|c|c|}
\hline \multirow[t]{2}{*}{ Cultural dimension } & \multicolumn{3}{|c|}{ Learning style } \\
\hline & \begin{tabular}{l}
\multicolumn{1}{c}{ Deep } \\
(relating ideas and \\
using evidence; an \\
interest in new ideas \\
and a willingness to \\
explore them in \\
depth).
\end{tabular} & $\begin{array}{l}\quad \text { Surface } \\
\text { (focus on } \\
\text { memorization, being } \\
\text { extrinsically } \\
\text { motivated by the fear } \\
\text { of failure, and focus } \\
\text { strictly on the task at } \\
\text { hand) }\end{array}$ & $\begin{array}{l}\quad \text { Strategic } \\
\text { (Organized } \\
\text { studying, good } \\
\text { time management, } \\
\text { achieving } \\
\text { motivation, and } \\
\text { monitoring } \\
\text { effectiveness) }\end{array}$ \\
\hline $\begin{array}{l}\text { Power distance (the } \\
\text { extent to which the less } \\
\text { powerful members of } \\
\text { organizations and } \\
\text { institutions accept and } \\
\text { expect power to be } \\
\text { distributed unequally) }\end{array}$ & Negative & Positive & No relationship \\
\hline $\begin{array}{l}\text { Collectivism (the degree } \\
\text { to which individuals are } \\
\text { expected to look after } \\
\text { themselves or remain } \\
\text { integrated with their family or } \\
\text { colleague groups) }\end{array}$ & Negative & Positive & Positive \\
\hline $\begin{array}{l}\text { Uncertainty avoidance } \\
\text { (the level of stress in a } \\
\text { society in the face of an } \\
\text { unknown future; the way } \\
\text { uncertainties are viewed and } \\
\text { taken care of) }\end{array}$ & $\begin{array}{l}\text { Positive to } \\
\text { moderately } \\
\text { positive }\end{array}$ & Negative & Positive \\
\hline $\begin{array}{l}\text { Short term orientation } \\
\text { (the extent to which a culture } \\
\text { programs its members to } \\
\text { accept delayed gratification } \\
\text { of their material, social and } \\
\text { emotional needs) }\end{array}$ & Negative & Positive & Positive \\
\hline $\begin{array}{l}\text { Masculinity vs. Feminity } \\
\text { (the division of emotional } \\
\text { roles between men and } \\
\text { women, manifesting itself as } \\
\text { aggressive versus more } \\
\text { "obedient" behaviour) }\end{array}$ & Positive & No relationship & Positive \\
\hline
\end{tabular}




\section{Implications for theory}

The main contribution of this paper would be to generate a stream of research to link cultural attributes to learning preferences using a conceptually different, though much less used approach, namely, that of Entwistle. To our knowledge, this has been the first attempt to use the approaches to learning variables and relate them to cultural attributes in a generalised framework. By understanding how cultural variables affect approaches to learning, one could go further into what can be done to reorient students going into an alien learning environment.

We have not developed the theory on how the cultural attributes are likely to affect each of the subscales on approaches to learning. This would be an obvious follow-up for theory development, and by pinpointing to which of the subscales actually contribute to the impact on the overall variable (such as deep learning), the theory could be made much sharper.

A great opportunity for theory development would be if a researcher could integrate the two approaches of Kolb and Entwistle into a single coherent framework. Then the rich theoretical advances made by scholars using Kolb's framework could be made use of by the fewer but perhaps more practice oriented approach using Entwistle's ideas.

\section{Implications for practice}

By focusing on the approaches to learning rather than to more fundamental constructs of learning styles, perhaps a more practical understanding of how students in a different environment learn, what their difficulties are, to what extent these are due to the cultural assumptions they have in their own minds, and what preparatory work could be useful. This preparatory work could be by devising training programmes aimed at reducing the culture shock and enabling a quicker adjustment. The cultural context of education plays an important role in understanding how and why students react in a particular manner to a learning environment. Since students need to understand the learning environment, especially when they are in a new environment, if they wish to maximise their academic success, the framework developed here would, if validated through an empirical study, help them to better understand how their own cultural predilections may need to change and what kind of changes are needed, and how they can adapt their approaches to learning to match the expectations of a particular learning environment. For example, an American or German student visiting India or Japan on an exchange programme might find some of the practices in the higher education system in India strange. They may question or dispute the teacher in the class during a lecture and the Indian teacher could interpret this interruption as disrespect to his/her authority in the subject, for silence during lectures in India and Japan is indicative of respect and a sign of attention being paid to the knowledge being imparted. The challenge of the exchange students may be to still acquire a depth in their learning in this new situation. On the other hand, an Indian student studying in Germany or USA could initially react to the alien environment using known parameters, in which case they might come across as non-assertive passive students rather than active generators of knowledge. Their challenge would be how to cope in a system that expects much greater independence in thinking and arriving at their own answers rather than expecting the teacher to hand over that knowledge in a platter. 
Teachers dealing with students from different cultures would benefit by understanding how the learning approaches of students from different cultures differ, and could deliver their courses with greater sensitivity to their diverse needs. For example, teachers could devote certain kinds of attention to students from specific cultural backgrounds by devising exercises that encourage deeper learning, counselling sessions to enable a more strategic approach to encourage better efficiency in their studies, or even just bring their learning habits to their attention in feedback sessions. This could improve the academic performance of students.

\section{Empirical validation}

The hypotheses generated in this paper would need to be validated through an empirical study. We see no difficulty in conducting such a study. An empirical study has indeed been done by us and some other colleagues and we are encouraged by the trend in the results so far. The full details of the study would be available in the forthcoming book by Keuchel, Neubauer and Anuradha (2007). In an empirical study, the approaches to learning could be measured through well established questionnaires such as ASSIST (Approaches and Study Skills Inventory for Students) developed by Entwistle and others. Of course, they would need a validation in the countries they are tested on, since these questionnaires also have been developed in a particular cultural context. The cultural characteristics of countries are readily available in Hofstede's work referenced; if a researcher prefers to use the more recent GLOBE version that could also be done without major rework on the theory developed.

\section{References}

Argyris, C. and Schon, D. (1978) Organizational learning: creating, retaining and transferring knowledge. Norwell, MA: Kluwer Academic Publishers.

Atkinson, J.W. and Feather, N.T. (1966) A Theory of Achievement Motivation. New York, NY: Wiley.

Auyeung, P. and Sands, J. (1996) 'A cross cultural study of learning styles of accounting students', Accounting and Finance, Vol. 36, pp.261-274.

Benedict, R. (1946) The Chrysanthemum and the Sword: Patterns of Japanese Culture. Boston, MA: Houghton Mifflin.

Biggs, J.B. (1987) Study Process Questionnaire Manual. Melbourne, Australia: Australian Council for Educational Research.

Biggs, J., Kember, D. and Leung, D.Y.P. (2001) 'The revised two-factor study process questionnaire: R-SPQ-2F', British Journal of Educational Psychology, Vol. 71, pp.133-149.

Coffield, F., Moseley, D., Hall, E. and Ecclestone, K. (2004) Should We Be Using Learning Styles? What Research Has To Say To Practice. London, UK: The Learning and Skills Research Centre (Monograph).

De Vita, G. (2001) 'Learning styles, culture and inclusive instruction in the multicultural classroom: a business and management perspective', Innovations in Education and Teaching International, Vol. 38, pp.165-173.

Emde, R.N. and Oppenheim, D. (1995) 'Shame, guilt, and the oedipal drama: developmental considerations concerning morality and the referencing of critical others', in J.P. Tangeny and K.W. Fischer (Eds), Self-Conscious Emotions: The Psychology of Shame, Guilt, Embarrassment, and Pride (pp.413-436). New York, NY: Guilford Press. 
Entwistle, N.J. (1992) The Impact of Teaching on Learning Outcomes in Higher Education. Sheffield, UK: Universities' and Colleges Staff Development Unit (Mimeo).

Entwistle, R.N. and Ramsden. P. (1983) Understanding Student Learning. London, UK: Croom Helm.

Entwistle, N.J. and Tait, H. (1995) The Revised Approaches to Studying Inventory. Edinburgh, UK: University of Edinburgh Centre for Research on Learning and Instruction (Mimeo).

Entwistle, R.N. and Wilson, J. (1970) 'Personality, study methods and academic performance', University Quarterly, Vol. 24, pp.147-156.

Entwistle, N.J., Hanley, M. and Hounsell, D. (1979) 'Identifying distinctive approaches to studying', Higher Education, Vol. 8, pp.365-380.

Entwistle, N.J., Tait, H. and McCune, V. (2000) 'Patterns of response to an approaches to studying inventory across contrasting groups and contexts', European Journal of the Psychology of Education, Vol. 15, pp.33-48.

Experienced Based Learning Systems (2007) Experiential Learning Bibliography, 1971-2005; 2005-2006. Downloaded in January 2007, Available at: http:// www.learningfromexperience.com/research-library/.

Hall, E.T. (1990) The Silent Language. New York, NY: Anchor Books.

Hansen, K. and Keuchel, S. (2005) 'Cross-cultural learning: differences and similarities between EU and ASEAN students. Method and core results', Paper presented in the Proceedings of the First International Conference on Intercultural Communication Competence: Implications for Business, Education and Politics, Singapore October 5-7, CD ISBN 981-05-4450-2.

Hofstede, G. (1980) Culture's Consequences. Beverly Hills, CA: Sage.

Hofstede, G. (1986) 'Cultural differences in teaching and learning', Int. J. Intercultural Relations, Vol. 10, pp.310-320.

Hofstede, G. (2001) Culture's Consequences (2nd ed.). Thousand Oaks, CA: Sage.

Hofstede, G. (2002) 'Europe: strengths and pitfalls of diversity', Paper presented in the Proceedings of the 2nd International Conference on Human Resource Management in Europe Trends and Challenges, Athens University of Economics and Business, Athens, October 17, Available at: http://www.mbc.aueb.gr/hrconference/application.htm.

Honey, P. and Mumford, A. (1982) The Manual of Learning Styles. Maidenhead, UK: Peter Honey.

House, R.J., Hanges, P.J., Javidan, M., Dorfman, P.W. and Gupta, V. (2004) Culture, Leadership and Organizations: The GLOBE Study of 62 Societies. Thousand Oaks, CA: Sage Publications.

Ingelhart, R. and Oyserman, D. (2004) 'Individualism, autonomy and self-expression: the human development syndrome', in H. Vinken and P. Ester (Eds), Comparing Cultures: Dimensions of Culture in a Comparative Perspective (pp.74-96). Leiden, The Netherlands: Brill.

Jaju, A., Kwak, H. and Zinkhan, G.M. (2002) 'Learning styles of undergraduate business students: a cross cultural comparison between US, India and Korea', Marketing Education Review, Vol. 12, pp.49-60.

Jarvis, P. (1987) Adult Learning in the Social Context. London, UK: Croom Helm.

Jarvis, P. (1995) Adult and Continuing Education. Theory and Practice (2nd ed.), London, UK: Routledge.

Kainzbauer, A. and Haghirian, P. (2005) 'Teaching across cultures: European teaching experience in Asian business classrooms', Paper presented in the Proceedings of the First International Conference on Intercultural Communication Competence: Implications for Business, Education and Politics, Singapore. CD ISBN 981-05-4450-2.

Keuchel, S., Neubauer, M. and Anuradha, N.S. (Eds) (2007) Cross Cultural Approaches to Learning and Studying: A Comparative Study on Austria, Germany, and India. New Delhi, India: MacMillan.

Kolb, D.A. (1976) Learning Style Inventory: Technical Manual. Boston, MA: McBer and Company. 
Kolb, D.A. (1984) Experiential Learning: Experience as the Source of Learning and Development. Englewood Cliffs, NJ: Prentice Hall.

Kolb, D.A. (1985) LSI Learning-Style Inventory. Boston, MA: McBer and Company.

Kolb, D.A. and Fry, R. (1975) 'Toward an applied theory of experiential learning', in C. Cooper (Ed.), Theories of Group Processes (pp.33-57). New York, NY: Wiley.

Marton, F. and Saljö, R. (1976) 'On qualitative differences in learning. 1. Outcome and process', British Journal of Educational Psychology, Vol. 46, pp.4-11.

Marton, F., Hounsell, D. and Entwistle, N. (Eds) (2005) The Experience of Learning: Implications for Teaching and Studying in Higher Education (3rd internet ed.). Edinburgh, UK: University of Edinburgh, Centre for teaching, Learning and Assessment.

Morse, K. (2003) 'Does one size fit all? Exploring asynchronous learning in a multicultural environment', Journal of Asynchronous Learning Networks, Vol. 7, pp.37-55.

Nisbett, R.E. (2003) The Geography of Thought: How Asians and Westerners Think Differently. New York, NY: Free Press.

Oyserman, D., Coon, H.M. and Kemmelmeier, M. (2002) 'Rethinking individualism and collectivism: evaluation of theoretical assumptions and meta-analyses', Psychological Bulletin, Vol. 128, pp.3-72.

Pask, G. (1976) 'Styles and strategies of learning', British Journal of Educational Psychology, Vol. 46, pp.128-148.

Paul, B. and Arcodia, C. (2002) 'Linking learning style preferences and ethnicity: international students studying hospitality and tourism management in Australia', Journal of Hospitality, Leisure, Sport and Tourism Education, Vol. 1, pp.15-27.

Piaget, J. (1952) The Origins of Intelligence in Children. New York, NY: International Universities Press.

Pratt, D.D. (1992) 'Conceptions of teaching', Adult Education Quarterly, Vol. 42, pp.203-220.

Ramburuth, P. (2001) 'Cross cultural learning behaviour in higher education: perceptions versus practice', Paper Presented in the Proceedings of the Seventh International Literacy and Education Research Network (LERN) Conference on Learning, RMIT University, Melbourne, 5-9 July 2000, Available at: http://ultibase rmit edu.au/Articles/may01/ramburuth1.htm.

Schmalzer, T. and Neubauer, M. (2007) 'Learning and studying across cultures', in T. Schmalzer, G. Apfelthaler, K. Hansen and R. Singh (Eds), Intercultural Communication Competence: Implications for Learning and Teaching in a Globalized World. New Delhi, India: Macmillan.

Smith, M.K. (2001) 'David A. Kolb on experiential learning', The Encyclopedia of Informal Education, Available at: http://www.infed.org/b-explrn.htm.

Tait, H., Entwistle, N.J. and McCune, V. (1998) 'ASSIST: a re-conceptualisation of the approaches to studying inventory', in C. Rust (Ed.), Improving Students as Learners (pp.262-271). Oxford, UK: Oxford Brookes University, Centre for Staff and Learning Development.

Taylor, R.L. (1990) The Religious Dimensions of Confucianism. Albany, NY: State University of New York Press.

Von Queis, D. (2005) 'Teaching and learning in different cultures: requirements for culturally sensitive instruction', Paper presented in the Proceedings of the First International Conference on Intercultural Communication Competence: Implications for Business, Education and Politics, Singapore, October 5-7. CD ISBN 981-05-4450-2.

Yamazaki, Y. (2005) 'Learning styles and typologies of cultural differences', Paper presented in the Proceedings of the First International Conference on Intercultural Communication Competence: Implications for Business, Education and Politics, Singapore, October 5-7. CD ISBN 981-05-4450-2. 